\title{
Managing Cost-Based Risks in Construction Supply Chains: A Stakeholder-Based Dynamic Social Network Perspective
}

\author{
Handong Tang, ${ }^{1}$ Ge Wang, ${ }^{2,3}$ Yanyan Miao, ${ }^{1}$ and Peng Zhang $\mathbb{D}^{4}$ \\ ${ }^{1}$ Department of Construction Management, Jiangxi University of Finance and Economics, Nanchang 330013, China \\ ${ }^{2}$ College of Public Administration, Huazhong Agricultural University, Wuhan 430070, China \\ ${ }^{3}$ Antai College of Economics and Management, Shanghai Jiao Tong University, Shanghai, 200030, China \\ ${ }^{4}$ School of Public Affairs, Chongqing University, Chongqing 400044, China \\ Correspondence should be addressed to Peng Zhang; zpmx123@163.com
}

Received 2 August 2020; Revised 20 September 2020; Accepted 4 October 2020; Published 22 October 2020

Academic Editor: Xianbo Zhao

Copyright (c) 2020 Handong Tang et al. This is an open access article distributed under the Creative Commons Attribution License, which permits unrestricted use, distribution, and reproduction in any medium, provided the original work is properly cited.

\begin{abstract}
In construction projects, cost-related risks are challenges that need to be coped with. These cost-related risks interact with each other along with the project progress and involve different stakeholders, forming a stakeholder-cost risk network. Previous studies have discussed the stakeholder-cost risk network; however, few studies have considered its dynamic characteristics. Different from traditional methods, this study employed the social network analysis (SNA) to explore the key indicators of cost-related risks within the supply chain and identify the key risks and stakeholders across four project stages: the planning start-up stage, design preparation stage, construction period, and operations and maintenance period. From a horizontal point of view (i.e., network development process), the complexity of the stakeholder-cost risk network demonstrates a U-shaped development process during the project life cycle, ranging from simple to complex to simple. From a vertical point of view (i.e., network hierarchical characteristics), the important cost-based risks are diversified within each stage. The current study contributes to forming a better understanding of the stakeholder-cost risk network from a dynamic perspective as well as the crucial cost-based risks within each stage of the project. The findings provide implications for managers to better align cost-based risk intervention strategies, thereby facilitating the achievement of construction project success.
\end{abstract}

\section{Introduction}

Serious cost-related problems have been identified in largescale projects over many years, including projects to construct large-scale structures such as highways, bridges, and airports $[1,2]$. These projects include many project stakeholders, with coordination difficulties from beginning to end, making it difficult for managers to take effective action to control cost-based risks. For example, Salling and Leleur [1] conducted a study of large transport projects and found that improper cost risk management by owners led to cost overruns in the design phase. Flyvbjerg et al. [3] conducted a survey of 258 highway and railway projects and found that 90 percent of cost overruns were caused by improper cost risk management.
The life cycle of engineering construction projects, especially large-scale projects, is becoming increasingly complex, and the cost-related challenges and risks are also increasing daily. Because of the increasingly large-scale and complex construction projects, the supply chains have changed from a simple linear chain structure to a complex network structure. As a result, cost-based risks have evolved from single-organization management to multiorganization management, based on collaborative work $[4,5]$. Complex stakeholder-related problems are often faced in construction projects $[6,7]$.

Applying stakeholder theory based on a meta-analysis in the project context shows that stakeholder management is very important for successfully implementing many kinds of projects, especially engineering construction projects $[8,9]$. 
Different stakeholders may have different goals during project development. When there is a diversity of stakeholders, their goals may conflict [10] and if expectations and interests are not met, it may hinder project success $[11,12]$. Therefore, in a construction project, more theoretical and practical efforts are needed to effectively manage the two key issues of cost-related risk management and stakeholder management.

In engineering construction projects, cost-related risks usually reflect conflicts of interest among different stakeholders at different project stages, such as price increases in raw materials, project delays at all levels, and changes in interest rates of financial institutions [2, 13]. At different stages of project development, the stakeholders in the supply chain network of construction projects change dynamically, and the risk network has different characteristics at different stages. In past research on the supply chain risk management of construction projects, many studies have applied a social network analysis (SNA) to evaluate stakeholders and risk networks based on network methods. For example, Mok et al. [14] applied SNA to study the major risk challenges in major projects, and Yu et al. [15] applied SNA to assess the social risks in the process of urban demolition.

However, most previous studies have taken a static consideration of the overall risk but do not address the dynamic characteristics of the risk network. In real projects, the risk network is a dynamic one that is fully integrated with stakeholders; as the project develops, new nodes are added and existing nodes disappear. In the course of dynamic development, the topological characteristics of the network change; as such, discussing the cost-related risks of the project supply chain requires dynamically analyzing the risk network in different stages.

Traditional network analysis uses aggregated static networks within a time interval. However, when the topological structure of the network changes sharply, the static aggregation network analysis becomes less accurate. Converged networks underestimate the importance of some nodes because important nodes in a certain period of time may seem less important in the converged network. For example, when considering the cost-related risks of the project, the people around them are more important during the land expropriation stage compared to the construction stage. In the increasingly complex supply chain system of construction projects, these knowledge gaps may lead to ineffective risk management [15]. Therefore, the objectives of this research were as follows:

(i) Through literature analysis and expert interviews, the study constructed a stakeholder-cost risk network for each project stage

(ii) Based on the multistage social network analysis, this study explored cost-related risks and their interrelationship in construction project supply chains from a stakeholder perspective

(iii) Based on the results of stage-by-stage social network analysis, this study proposed a strategy for managing supply chain stakeholders and cost-related risks

The study identified 29 cost-related risks by linking cost risk management and stakeholder management in different stages of the construction project. The research found that the most significant cost-related risks in the design preparation stage include difficulties in land acquisition, embezzlement and bribery, and inaccurate cost estimations of the owner's project. The most important cost-related risks during the construction period include inaccurate contractor cost estimates, changes in material prices, and contractor delays in the construction period. Finally, during the operation and maintenance period, legal disputes and the adverse impact of the construction project on the environment become more important.

\section{Literature Review}

2.1. Stakeholders in a Construction Project Supply Chain. A construction project supply chain is an organic combination of all businesses and organizations in the entire process, from conceptual design to building abandonment $[16,17]$. Smoothly completing construction projects usually requires the cooperation of multiple organizations or departments. During project start-up and implementation, different stakeholders are involved in project construction. The collaborative relationships related to the project bring the parties together, expanding the project's scale and creating the project supply chain [18]. A stakeholder refers to "any group or individual who may affect or be affected by the achievement of organizational goals" [19]. Oppong et al. [20] and Xia et al. [21] noted that construction project stakeholders have a wide range of economic and social impacts. Different definitions of project stakeholders by different scholars (Table 1) indicate that stakeholders can be divided into major stakeholders that are directly related to the project and secondary stakeholders that are not directly involved in the project.

Based on these scholarly definitions, this study included stakeholders referenced by two or more scholars (Figure 1). Clients, owners, contractors, designers, suppliers, and governments are directly linked to megaconstruction projects. They often significantly influence sustainable construction and are considered to be primary stakeholders. Secondary stakeholders mainly refer to assessment organizations, scientific research institutions, and surrounding people who do not directly participate in the project construction process.

2.2. Cost Risk in Construction Project Supply Chain. The supply chain of engineering construction project is a free system composed of many enterprises, and there are many risks in the structure of this system [26, 27]. The Project Management Institute defines "project risk" as uncertain events or conditions that may occur during the project or factors that may have an uncertain impact on the 
TABLe 1: Definition of stakeholders in construction projects by different scholars.

Author/time
$\begin{aligned} & \text { Johansson [22] } \\ & \text { Clients, owners, contractors, designers, suppliers, financial organizations, government, researchers, and surrounding } \\ & \text { people }\end{aligned}$
$\begin{aligned} & \text { Zhou and Yang } \\ & \text { [23] }\end{aligned}$
$\begin{array}{r}\text { Clients, consultants, contractors, subcontractors/suppliers, end-users, financial organizations, government, } \\ \text { environmental protection organizations, professional associations, media, the public, trade unions, evaluators/ } \\ \text { certifiers, and researchers/educators }\end{array}$
$\begin{array}{r}\text { Yang and Shen } \\ \text { Government, financiers, developers, consultants, suppliers, designers, owners, supervisors, contractors, } \\ \text { subcontractors, and end-users }\end{array}$
$\begin{array}{r}\text { Mok et al. [14] } \\ \text { Clients, contractors, consultants, suppliers, end-users, governments, financiers/sponsors, communities, district } \\ \text { councils, the general public, competitors, utilities, special interest groups, and the media }\end{array}$
Clients, consultants, the main contractor, engineers, subcontractors, end-users, and others

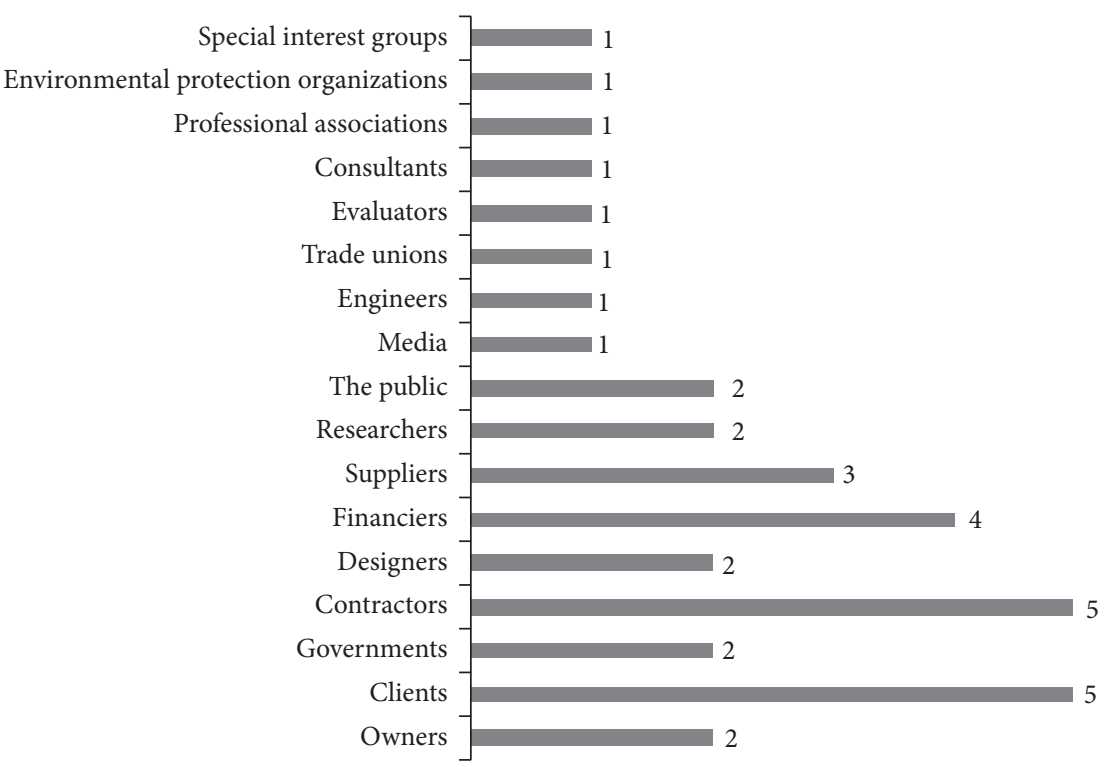

Figure 1: Frequency statistics of project stakeholders in the literature.

achievement of project objectives $[28,29]$. In terms of costrelated risks, researchers usually focus on activities or conditions that may negatively impact project costs $[1,30]$. Therefore, compared with other types of project risk, focusing on the risk of cost overruns reorients risk management from the traditional project objectives (duration, quality, and cost) to project cost $[3,31]$. Different project organizations may take significantly different approaches when focusing on cost-based risk management. For example, when owners focus on cost-based risk management, they emphasize controlling land prices and accurately budgeting costs [32]. For contractors, the emphasis of costbased risk management is to identify reasonable suppliers during the construction period to establish partnerships that stabilize material supply prices [33]. Across the supply chain, the costs and risks of different stakeholders are closely related [34-36]. In this respect, cost-based risk management is closely linked to most stakeholders in the supply chain of construction projects, as most risks are caused by stakeholder-related conflicts $[37,38]$.

The conflicts in interests among different stakeholders lead to many risks of cost overruns, which often hinder project success. To prevent cost overruns and to ensure successful project implementation, it is important to comprehensively assess cost-related risks [39, 40]. In construction projects, there has been extensive research on methods for managing cost-related risks. When studying cost-related risks in the Chinese construction market, Fang [41] divided cost-based risks into internal risk and external risk. The important internal risks include payment delays; insufficient technical or personnel reserves; and inadequate equipment, safety, and environmental management. External risks include factor price changes and financial policy and economic environment changes [42].

When evaluating cost-related risks, El-Sayegh [43] listed examples of important cost-related risks in construction projects as including economic environment changes, project delays, insufficient technical personnel reserves, improper interventions, and material supply changes. Tang et al. [33] divided cost-based risks into internal risk and external risks when studying the management of construction projects. Internal risks include design defects, payment delays, inaccuracies in orders or data, labor disputes, and third-party delays. External risks include inflation, adverse climatic conditions, and unpredictable physical conditions. Desai [44] found that different types of delays by different stakeholders in the supply chain are also sources of cost-based risk during the project process. Different scholars 
$[3,35,44,45]$ have organized different types of cost-based risks using a risk decomposition structure (RDS).

To improve the risk identification process, this study summarized cost-related risk categories in the literature to form a risk category network (Figure 2). An analysis of the risk category network concluded that the most widely accepted project cost-based risks can be divided into nine categories: accidental claim (D1), financial policy and economic environment changes (D2), engineering corruption (D3), insufficient environmental, equipment, and security management (D4), factor price changes (D5), insufficient technical reserves (D6), plan deviations (D7), project delays (D8), and an overly large upfront investment (D9).

With respect to the research methodology, previous studies have usually assessed the importance of cost-based risks based on the possibility of occurrence and the impact of different risks (examples include El-Sayegh [43] and Tang et al. [33]). Social network analysis (SNA) is a commonly used method to rank risks in construction projects $[15,46]$. This method usually uses the network characteristics of points and links in an aggregation network to measure the importance of risk but does not consistently consider the dynamic characteristics of each risk in the risk network.

Many scholars have outlined the shortcomings of static aggregation network; however, the impact of network characteristics in different project stages on risk assessment has not been fully quantified. The main purpose of a costbased risk assessment is to alleviate the cost-related problems in the construction project supply chain. A dynamic risk network assessment is an effective method for identifying the main risks at each project stage. Most of these risks involve stakeholders in the supply chain that enter and exit the risk network at different stages. Therefore, key needs for construction projects are to address the cost-related risks of supply chain stakeholders, to transform the aggregated static cost risk network into a stage-by-stage dynamic cost risk network, and to determine the key cost risks of different project stages and quantify their impact. According to the standard of the Project Management Institute (PMI) [29], this paper divides the project into four stages: starting the project, organizing and preparing, carrying out the work, and ending the project.

\section{Method}

SNA is presented by Moreno [47]. It is an analytical method combining graph theory sociology and anthropology theory. Traditional network analysis uses static networks or models that aggregate nodes interactions within time intervals. However, this analysis is limited because real systems evolve over time, and interactions between individuals typically exhibit intermittent and paroxysmal interactions [48]. To compensate for the defects of static networks and construct dynamic network models, Kempe [49] uses time information to construct temporal network model by adding time information into static graph so as to study connectivity and reasoning problem of dynamic network diagram. Ferreira [50] extends static sequential networks using a series of sequential network snapshots (static graphs within a period) to demonstrate evolution processes of events. This study assumed that the observation time of the network is limited, from the beginning of $T_{\text {star }}$ to the end of $T_{\text {over }}$. This creates a dynamic network $G_{0, T}^{X}=\left(\mathrm{V}, E_{0, T}\right)$, containing the finite point set $\mathrm{V}$ and finite time set $E_{0, T}$ in the time set $[0, \mathrm{~T}]$ when the time set is set to $T_{\text {star }}=0$ and $T_{\text {over }}=T_{0}$. In an aggregation network, the set of vertices $\mathrm{V}$ is always the same. In contrast, in a dynamic network, the set of vertices can change over time. The network characteristics in the dynamic network are realized by converting the time into multiple network snapshots. In other words, the dynamic network can be expressed as a series of static network graphs (Figure 3).

A network with $n$ node is denoted by $G=(V, E)$, where $V=\left\{V_{i} \mid i=1,2, \ldots, n\right\}$ is the node set; $E=\left\{\left(V_{i}, V_{j}\right) ; V_{i}\right.$ is the star node; $V_{j}$ is the end node; and i, $\left.j=1,2, \ldots, n\right\}$ is the edge set. The expression $A=\left(a_{i j}\right)_{n \times n}$ is the adjacency matrix of $G$, with the following elements:

$$
a_{i j}= \begin{cases}1, & \left(V_{i}, V_{j}\right) \in \mathrm{E}, \\ 0, & \left(V_{i}, V_{j}\right) \notin E,\end{cases}
$$

where $i, j=1,2, \ldots, n$.

Recognizing the importance of nodes in the dynamic network is largely determined by the structure of the nodes on the network. Designing the ranking index of nodes according to the network topology is an important method for identifying key nodes in dynamic networks. Most current methods are based on static topology index; this study considered the network density and node centrality. The network density was used to measure the compactness of nodes. The multidegree method was used to calculate the network density. The formula is as follows:

$$
\text { density }=\frac{L}{N}(N-1) \text {, }
$$

where $N$ and $L$ refer to the number of stakeholders and links, respectively.

Centrality is an attribute used to measure the degree of individual relevance. The position of a node in the network can be used to determine the degree of its power and the influence and limitation of the stakeholders. Centrality includes the degree centrality, betweenness centrality, and closeness centrality:

$$
\text { degree of centrality: } C_{D}\left(n_{i}\right)=\frac{d_{i}\left(n_{i}\right)}{N-1},
$$

where $d_{i}\left(n_{i}\right)$ refers to degree of node i. Also, 


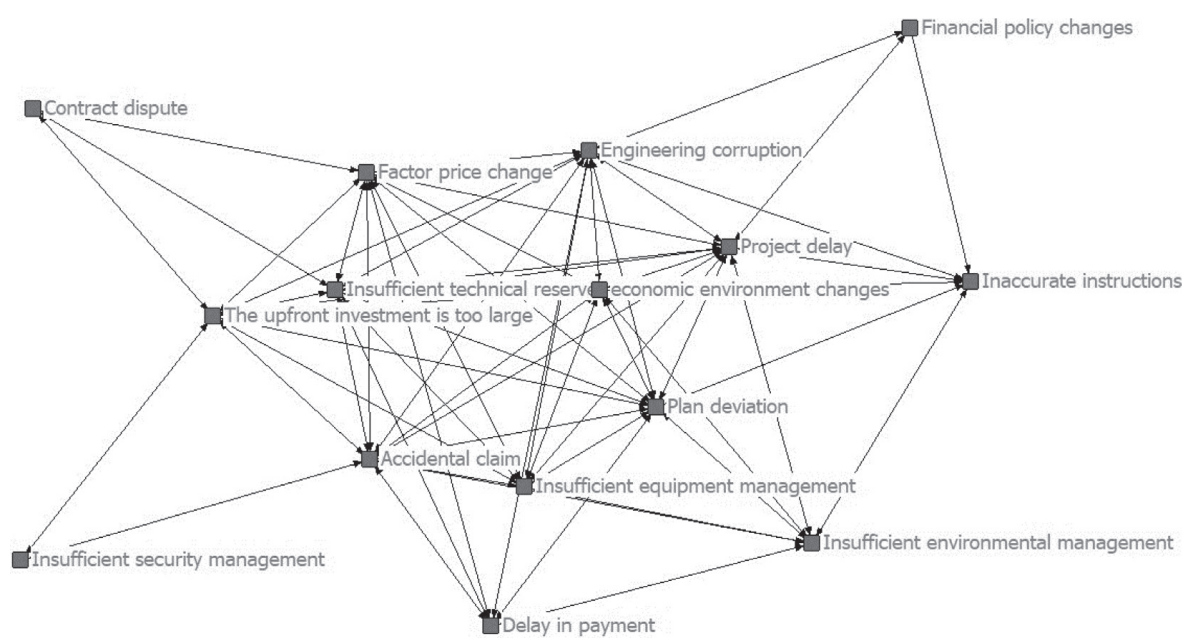

FIGURE 2: Risk category network.

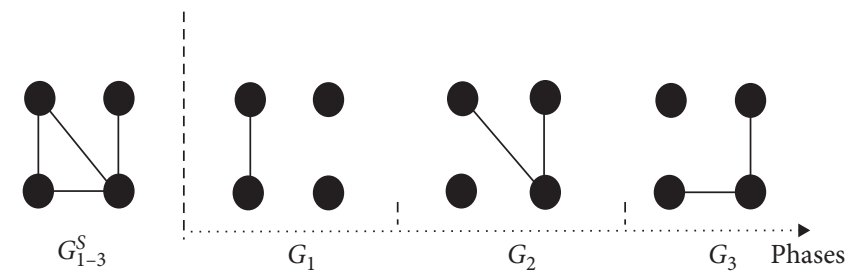

FIGURE 3: Comparison between aggregation graph representation and dynamic sequence representation.

betweeness centrality: $\left\{\begin{array}{l}C_{B}\left(n_{i}\right)=\frac{\sum g_{j k}\left(n_{i}\right) / g_{j k}}{(N-1)(N-2)}, \\ g_{j k}\left(n_{i}\right)=\left\{\begin{array}{l}g_{j i} \times g_{i k} d(j, i)+d(i, k)=d(s, t), \\ 0, \text { other. }\end{array}\right.\end{array}\right.$

In this expression, $g_{j k}$ indicates the number of shortcuts between point $j$ and point $k ; g_{j k}\left(n_{i}\right)$ refers to the number of shortcuts between two correlators, including the correlator $n_{i}$ :

$$
\text { closeness centrality : } C_{c}\left(n_{i}\right)=\frac{N-1}{\sum_{j=1}^{N} d\left(n_{i}, n_{j}\right)} \text {. }
$$

In this expression, $d\left(n_{i}, n_{j}\right)$ refers to the geodesic distance between node $n_{i}$ and node $n_{j}$.

3.1. Research Process. First, the cost-based risks and the period of their occurrence in the project supply chain were determined using a literature analysis and semistructured interviews. Background information and research content were sent to interviewees by email before the interview, so they could review their previous experience in construction projects and be prepared to discuss the issues. The interview questions mainly focused on the cost-related risks and related stakeholders in the construction project supply chain and the stages at which the risks occur.

In the second step, the interactions between the identified cost-related risks were analyzed based on the empirical knowledge of key stakeholders. To this end, face-to-face interviews were conducted to review respondent perspectives from nine identified stakeholder groups. Researchers verbally explained questions for participants when they did not clearly understand them to minimize ambiguity. Interviews required appropriate stakeholders to assess the direction and effectiveness of potential linkages.

In the third step, the data collected from steps 1 and 2 were imported into NetMiner 4 for risk network visualization and analysis. Previous studies have applied six indicators to reflect the main characteristics of the risk network and to identify key risks, linkages, and 
corresponding stakeholders. These indicators include network density, network cohesion, node degree, intermediate degree, state centrality, and intermediation. These are widely used in SNA research and effectively describe the key characteristics of networks, nodes, and links. Finally, we formulate the research framework of this study (Figure 4).

3.2. Data Collection. The literature analysis identified nine types of construction project stakeholders. By applying stakeholder sampling principles, 11 experts were selected for a pilot study (Table 2); an additional list of nine stakeholders in the construction project supply chain were invited to make further comments to ensure that the data were representative. Based on expert interviews, contacts were made with representatives from nine stakeholder groups and snowball sampling techniques were used to encourage more potential respondents to participate in the study [15]. A total of 120 potential respondents were invited throughout the data collection process; of these, 36 agreed to participate in the interview, with a response rate of $30 \%$. The interviewees had 5-20 years of work experience, mainly in government departments, scientific research institutions, planning and design enterprises, and construction companies. These respondents formed a discussion group that reduced ambiguity through public discussion and improved the reliability of the data by sharing information among different participants [23].

At the workshop, participants were asked to answer questions about the types of cost-related risk indicators and their links with stakeholders, focusing on "whether" and "how much" the risk indicators are linked to different stakeholders. Workshop participants in the workshop contributed to developing a matrix of indicators related to stakeholders. The matrix identified the possibilities and consequences of the impact between risks at five points. Some questions also used a Likert scale ( 1 for complete disagreement and 5 for complete agreement). This method is similar to the study conducted by $\mathrm{Li}$ and An [51]. Unclear questions were explained verbally to the interviewees to reduce ambiguity.

To visualize the data, a series of structural matrices were established to determine the relationship between stakeholders and indicators (Table 3). This step mainly defined the interaction between indicators. After data conversion, the matrix data were entered into NetMiner 4 software. This generated a network diagram showing the cost-based risk evaluation index and the status center map. In SNA, the first step is to identify the node. For this study, the symbol Si $(i=1,2-9)$ represented 9 stakeholders; the symbol Rj represented 29 evaluation indicators. For example, if S1R2 extends to S3R4, it means that S1R2 affects S3R4. The links in the risk network represent the impact between the two points. By analyzing the characteristics of the stakeholderdriven cost-based risk network, this study mainly analyzed the network density, network cohesion, node degree, intermediary, and position centrality. These indicators can reflect key nodes and key linkages in the network, resulting in key stakeholders and key evaluation indicators in the sustainable project network.

\section{Results and Analysis}

4.1. Network Analysis. In the cost-based risk network, the index related to each stakeholder is a network node. The importance of a node depends on the degree of centrality, which determines the ability of a node to interact with other nodes. Figure 5 presents the network nodes using nine shapes (e.g., circles, squares, and diamonds), representing nine different stakeholder groups. The nine colors at the node represent the nine dimensions of the indicator. The more external connections there are from the node, the greater the impact of the node. Some nodes have a very high density in the center. This means that these nodes play a central role in the full network. Figure 4 shows that nodes have more triangles, circles, and diamonds compared to the other shapes in the three-stage network. This indicates that most indicators are related to these three stakeholders: the owner, the government, and the contractor. The evaluation indicators related to these stakeholders' cover most of the network, which also reflects their importance. With respect to network complexity, the stakeholder-cost risk network develops from simple to complex and then to simple through the project life cycle.

This study also calculated the network density and cohesion and quantitatively examined the configuration of the cost risk network. The network density reflects overall network connectivity, and cohesion analyzes the complexity of the network by considering the accessibility of different nodes. Higher density or cohesion usually indicates that practitioners must address more challenges in risk management $[15,38]$. The network density in the preparation phase of the design is 0.3091, and the average distance between the two nodes is 1.431 steps. The network density in the construction phase is 0.056 , and the average distance between the two nodes is 3.418 steps; network density in the operation and maintenance phase is 0.35 , and the average distance between the two nodes is 1.75 steps. This shows that the networks are dense, with nodes that are close to each other. However, the network appears denser in the design preparation stage and operation and maintenance stage compared to the construction phase.

4.2. Node and Link Level Analysis. Four other indicators were calculated for the node-level analysis: self-network size, external centrality, degree, and degree of difference (Table 4). These indicators reflect the characteristics and influence of risk nodes from different perspectives. If a risk has a large self-network scale, then many risks are closely related to this risk. External centrality reflects the range of influence: the higher the degree is, the greater the range of influence is. The difference is the difference between the degree and the degree. The larger the difference is, the greater the impact of this node is, compared with the impact of other nodes on the node. The risks in the top five of these four indicators are shown below (Table 4).

Finally, the centrality between different nodes and links was analyzed, as well as the extent to which the risk or interaction can control the impact, that is, the ability to 


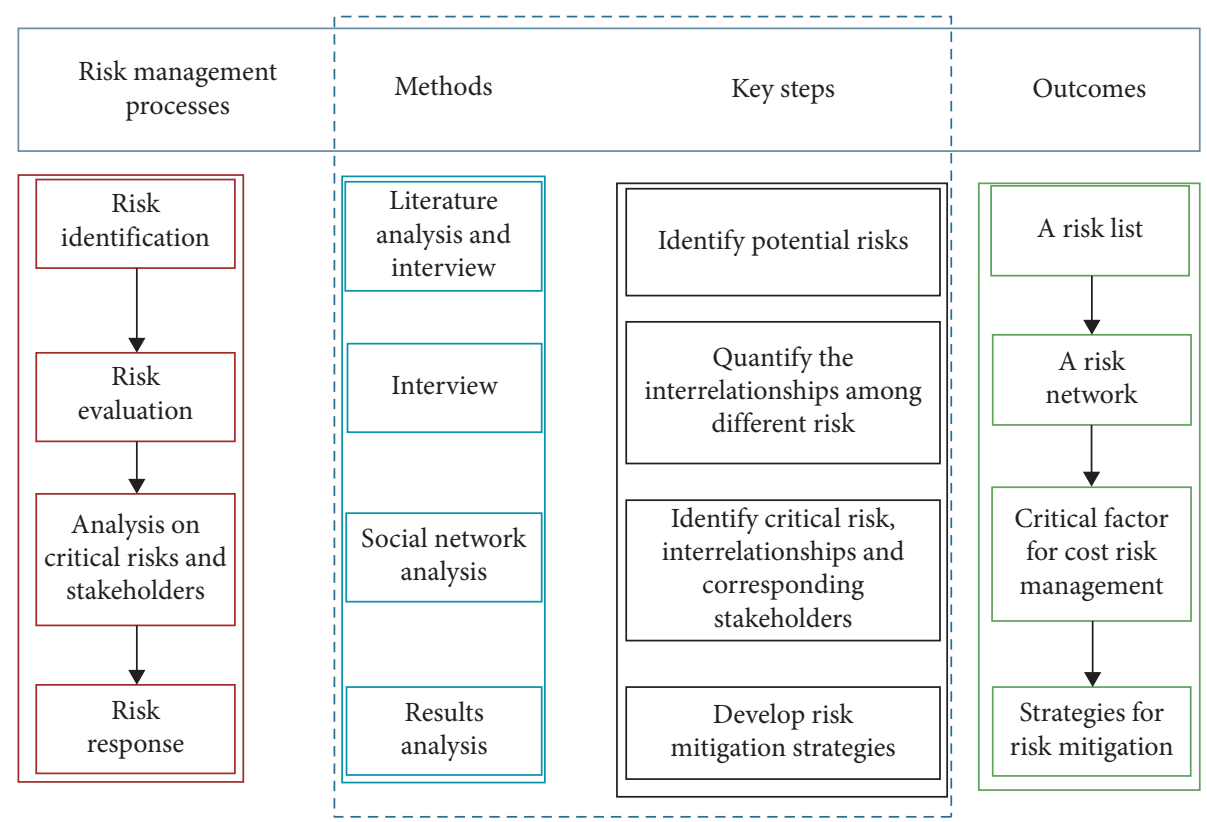

FIgURE 4: Main research framework.

TABLE 2: The roles of experts participating in the interview.

\begin{tabular}{lcccc}
\hline Organization & Role of interviewee & Ages & Experience in construction & Number of projects involved \\
\hline Construction company & Senior engineer & 36 & 10 & 3 \\
Construction company & Project manager & 38 & 12 & 4 \\
Government & Head of department & 56 & 24 & 14 \\
Research institutions & Professor A & 55 & 25 & 9 \\
Research institutions & Professor B & 54 & 24 & 8 \\
House builder & Consultant A & 38 & 14 & 4 \\
House builder & Developer & 45 & 25 & 7 \\
Suppliers & Sales supervisor & 45 & 17 & 20 \\
Design company & Consultant B & 41 & 14 & 14 \\
Design company & Designer & 38 & 15 & 12 \\
Financial organizations & Manager & 40 & & 25 \\
\hline
\end{tabular}

control influence. Table 5 shows the nodes and links arranged in the middle. Eliminating these risks or interactions can significantly reduce the complexity of the risk network.

The most important cost-related risk categories in the design preparation stage include excessive early investment and project corruption. The related stakeholders are owners and government departments. The specific risks include difficulties in obtaining land, embezzlement and bribery, and inaccurate cost estimations for the owner's project. This highlights the importance of reducing, preventing, and controlling the occurrence and development of engineering corruption in these two stakeholder groups.

During the construction period, with a large number of stakeholders entering the project supply system, the stakeholder-cost risk network becomes more complex. The owner and contractor have the greatest impact on the risk of project cost overruns. The most important cost-related risks include the inaccurate estimation of the contractor's cost, delays of the contractor's deadlines, and changes in material price. When the construction phase is completed, the project enters the operational phase. A large number of stakeholders are separated from the project supply chain network, and the surrounding people and owners have a greater impact at this stage. The adverse impact of construction projects on the environment and legal disputes become important costrelated risks in this phase.

\section{Discussion}

Using a dynamic perspective, this study developed a stakeholder-cost risk network in different project stages and applied a social network analysis to analyze the stakeholdercost risk network structure in different stages. The costrelated risks were evaluated according to the topological structure changes and network characteristics in each stage. From a horizontal point of view (i.e., network development process), the complexity of stakeholder-cost risk network exhibits a U-shaped development, evolving from simple to complex and then back to simple as the project cycle proceeds. From the vertical point of view, considering the network characteristics of each period, the prominent stakeholders and cost risks of each stage differ compared to 
TABLE 3: Cost-related risks and their linked stakeholders.

\begin{tabular}{|c|c|c|c|c|c|}
\hline $\begin{array}{l}\text { Risk } \\
\text { number }\end{array}$ & Types of risks & Stakeholder & $\begin{array}{l}\text { Index } \\
\text { ID }\end{array}$ & References & Category \\
\hline$R_{1}$ & Inability to obtain land and access rights & $\begin{array}{l}S_{2} \\
S_{1}\end{array}$ & $\begin{array}{l}S_{2} R_{1} \\
S_{1} R_{1}\end{array}$ & $\begin{array}{l}\text { Hilber and Robert-Nicoud [52] } \\
\text { Turner and Henryks [53] }\end{array}$ & $D_{9}$ \\
\hline$R_{2}$ & $\begin{array}{c}\text { Compensation costs higher than } \\
\text { expected }\end{array}$ & $\begin{array}{l}S_{2} \\
S_{1}\end{array}$ & $\begin{array}{l}S_{2} R_{2} \\
S_{1} R_{2}\end{array}$ & $\begin{array}{l}\text { Hilber and Robert-Nicoud [52] } \\
\text { Turner and Henryks [53] }\end{array}$ & $D_{9}$ \\
\hline$R_{3}$ & Legal dispute & $S_{2}$ & $S_{2} R_{3}$ & Funderburg et al. [54] & $D_{1}$ \\
\hline$R_{4}$ & Threats to personal or asset security & $\begin{array}{l}S_{2} \\
S_{9}\end{array}$ & $\begin{array}{l}S_{2} R_{4} \\
S_{9} R_{4}\end{array}$ & $\begin{array}{c}\text { Alinaitwe et al. [55] } \\
\text { Gross [56] }\end{array}$ & $D_{4}$ \\
\hline$R_{5}$ & Third-party claims & $\begin{array}{l}S_{2} \\
S_{4}\end{array}$ & $\begin{array}{l}S_{2} R_{5} \\
S_{4} R_{5}\end{array}$ & $\begin{array}{l}\text { Alinaitwe et al. [55]; Gross [56] } \\
\text { Al-Momani [57] }\end{array}$ & $D_{1}$ \\
\hline$R_{6}$ & Costs due to disputes and community & $S_{1}$ & $S_{1} R_{6}$ & Söderholm [58] & $D_{4}$ \\
\hline$R_{7}$ & Ambiguity of project scope & $\begin{array}{l}S_{4} \\
S_{3}\end{array}$ & $\begin{array}{l}S_{4} R_{7} \\
S_{3} R_{7}\end{array}$ & $\begin{array}{l}\text { Ghosh and Jintanapakanont [59] } \\
\text { Kaliba et al. [60] }\end{array}$ & $D_{7}$ \\
\hline$R_{8}$ & Ground condition change & $S_{4}$ & $S_{4} R_{8}$ & $\begin{array}{c}\text { Ghosh and Jintanapakanont [59] } \\
\text { Lo et al. [61] }\end{array}$ & $D_{4}$ \\
\hline$R_{9}$ & Inadequate project complexity analysis & $\begin{array}{l}S_{3} \\
S_{4}\end{array}$ & $\begin{array}{l}S_{3} R_{9} \\
S_{4} R_{9}\end{array}$ & $\begin{array}{l}\text { Arain et al. [62]; Brockmann [63] } \\
\text { Nielsen and Randall [64] }\end{array}$ & $D_{7}$ \\
\hline$R_{10}$ & Unforeseen modification to project & $\begin{array}{l}S_{2} \\
S_{4} \\
S_{2}\end{array}$ & $\begin{array}{l}S_{2} R_{10} \\
S_{4} R_{10} \\
S_{2} R_{11}\end{array}$ & Ghosh and Jintanapakanont [59] & $D_{7}$ \\
\hline$R_{11}$ & Inaccurate project cost estimate & $\begin{array}{l}S_{4} \\
S_{4} \\
S_{5}\end{array}$ & $\begin{array}{l}S_{4} R_{11} \\
S_{4} R_{12} \\
S_{5} R_{12}\end{array}$ & Nielsen and Randall [64] & $D_{7}$ \\
\hline$R_{12}$ & Failure to meet specified standards & $\begin{array}{l}S_{3} \\
S_{7}\end{array}$ & $\begin{array}{l}S_{3} R_{12} \\
S_{7} R_{12}\end{array}$ & Arain et al. [62]; Arditi et al. [65] & $D_{6}$ \\
\hline$R_{13}$ & Engineering and design change & $S_{3}$ & $S_{3} R_{13}$ & Ghosh and Jintanapakanont [59] & $D_{7}$ \\
\hline$R_{14}$ & Project delays of all forms & $\begin{array}{l}S_{4} \\
S_{5} \\
S_{4}\end{array}$ & $\begin{array}{l}S_{4} R_{14} \\
S_{5} R_{14} \\
S_{4} R_{15}\end{array}$ & $\begin{array}{l}\text { Yang and Wei [66]; Fugar and Agyakwah [45]; } \\
\text { Nielsen and Randall [64] }\end{array}$ & $D_{8}$ \\
\hline$R_{15}$ & Equipment damage & $\begin{array}{l}S_{5} \\
S_{2} \\
S_{8} \\
S_{4}\end{array}$ & $\begin{array}{l}S_{5} R_{15} \\
S_{2} R_{16} \\
S_{8} R_{16} \\
S_{4} R_{16}\end{array}$ & Alarcon et al. [67] & $D_{4}$ \\
\hline$R_{16}$ & Change in government funding policy & $\begin{array}{l}S_{5} \\
S_{6} \\
S_{2} \\
S_{8} \\
S_{4}\end{array}$ & $\begin{array}{l}S_{5} R_{16} \\
S_{6} R_{16} \\
S_{2} R_{17} \\
S_{8} R_{17} \\
S_{4} R_{17}\end{array}$ & Curtis [36]; Haynes [68]; Hodge [69] & $\mathrm{D}_{2}$ \\
\hline$R_{17}$ & Taxation changes & $\begin{array}{l}S_{5} \\
S_{6} \\
S_{4} \\
S_{5}\end{array}$ & $\begin{array}{l}S_{5} R_{17} \\
S_{6} R_{17} \\
S_{4} R_{18} \\
S_{5} R_{18}\end{array}$ & Curtis [36]; Haynes [68] & $\mathrm{D}_{2}$ \\
\hline$R_{18}$ & Wage inflation & $\begin{array}{l}S_{2} \\
S_{6}\end{array}$ & $\begin{array}{l}S_{2} R_{18} \\
S_{6} R_{18}\end{array}$ & Fugar and Agyakwah [45]; Frimpong et al. [70] & $D_{5}$ \\
\hline $\begin{array}{l}R_{19} \\
S_{6}\end{array}$ & Local inflation change & $S_{1}$ & $\begin{array}{l}S_{1} R_{19} \\
S_{6} R_{20}\end{array}$ & $\begin{array}{l}\text { Fugar and Agyakwah [45] } \\
\text { Frimpong et al. [70] }\end{array}$ & $\mathrm{D}_{2}$ \\
\hline $\begin{array}{l}R_{20} \\
S_{4}\end{array}$ & Foreign exchange rate & $S_{5}$ & $\begin{array}{l}S_{5} R_{20} \\
S_{4} R_{20}\end{array}$ & Ghosh and Jintanapakanont [59] & $\mathrm{D}_{2}$ \\
\hline $\begin{array}{l}R_{21} \\
S_{5}\end{array}$ & Material price changes & $S_{4}$ & $\begin{array}{l}S_{4} R_{21} \\
S_{5} R_{21}\end{array}$ & Frimpong et al. [70] & $D_{5}$ \\
\hline$R_{22}$ & Energy price change/interest rate & $S_{6}$ & $S_{6} R_{22}$ & Frimpong et al. [70] & $\mathrm{D}_{2}$ \\
\hline $\begin{array}{l}R_{23} \\
S_{5}\end{array}$ & Catastrophic environmental effects & $S_{4}$ & $\begin{array}{l}S_{4} R_{23} \\
S_{5} R_{23}\end{array}$ & Chang and Wilmot [71]; Flyvbjerg et al. [3] & $D_{4}$ \\
\hline$R_{24}$ & $\begin{array}{l}\text { Adverse environmental impacts due to } \\
\text { construction work }\end{array}$ & $S_{9}$ & $S_{9} R_{24}$ & Lo et al. [61]; Flyvbjerg et al. [3] & $D_{4}$ \\
\hline$R_{25}$ & Unfavourable climate conditions & $\begin{array}{l}S_{4} \\
S_{5} \\
S_{1}\end{array}$ & $\begin{array}{l}S_{4} R_{25} \\
S_{5} R_{25} \\
S_{1} R_{26}\end{array}$ & $\begin{array}{l}\text { Flyvbjerg et al. [3]; Ghosh and Jintanapakanont } \\
\text { [59] }\end{array}$ & $D_{4}$ \\
\hline
\end{tabular}


TABLE 3: Continued.

\begin{tabular}{|c|c|c|c|c|c|}
\hline $\begin{array}{l}\text { Risk } \\
\text { number }\end{array}$ & Types of risks & Stakeholder & $\begin{array}{l}\text { Index } \\
\text { ID }\end{array}$ & References & Category \\
\hline$R_{26}$ & Embezzlement and bribery & $\begin{array}{l}S_{4} \\
S_{5} \\
S_{3}\end{array}$ & $\begin{array}{l}S_{4} R_{26} \\
S_{5} R_{26} \\
S_{3} R_{26}\end{array}$ & Cirilovic et al. [72] & $D_{3}$ \\
\hline$R_{27}$ & Political opposition/interferences & $S_{2}$ & $S_{2} R_{27}$ & Arrowsmith [35] & $D_{3}$ \\
\hline$R_{28}$ & Social instability & $S_{2}$ & $S_{2} R_{28}$ & $\begin{array}{c}\text { Curtis and Sturup [36] } \\
\text { Haynes [68] }\end{array}$ & $D_{2}$ \\
\hline$R_{29}$ & Delay in obtaining approval & $S_{2}$ & $S_{2} R_{29}$ & Kaliba et al. [60] & $D_{3}$ \\
\hline
\end{tabular}

TABLE 4: Ranking of key risks based on state centrality, self-network, and node degree analysis.

\begin{tabular}{lcccccccc}
\hline Project phases & Index ID & Out-status centrality & Index ID & Ego size & Index ID & Out-degree & Index ID & Degree difference \\
\hline \multirow{5}{*}{ Organizing and preparing } & $S_{2} R_{1}$ & 0.67 & $S_{2} R_{2}$ & 9 & $S_{2} R_{1}$ & 5 & $S_{2} R_{11}$ & 7 \\
& $S_{1} R_{26}$ & 0.66 & $S_{2} R_{1}$ & 8 & $S_{1} R_{26}$ & 5 & $S_{2} R_{2}$ & 5 \\
& $S_{2} R_{11}$ & 0.55 & $S_{1} R_{26}$ & 8 & $S_{2} R_{11}$ & 4 & $S_{2} R_{28}$ & 4 \\
& $S_{2} R_{28}$ & 0.55 & $S_{2} R_{11}$ & 7 & $S_{2} R_{28}$ & 4 & $S_{2} R_{27}$ & 4 \\
& $S_{1} R_{6}$ & 0.43 & $S_{1} R_{1}$ & 5 & $S_{2} R_{27}$ & 4 & $S_{2} R_{29}$ & 4 \\
\hline \multirow{5}{*}{ Carrying out the work } & $S_{2} R_{11}$ & 2.41 & $S_{4} R_{11}$ & 16 & $S_{4} R_{11}$ & 15 & $S_{4} R_{11}$ & 10 \\
& $S_{4} R_{11}$ & 2.22 & $S_{4} R_{14}$ & 15 & $S_{2} R_{11}$ & 14 & $S_{2} R_{11}$ & 10 \\
& $S_{4} R_{14}$ & 1.39 & $S_{4} R_{14}$ & 14 & $S_{2} R_{10}$ & 9 & $S_{2} R_{10}$ & 6 \\
& $S_{2} R_{10}$ & 1.27 & $S_{2} R_{10}$ & 12 & $S_{4} R_{14}$ & 9 & $S_{3} R_{13}$ & 6 \\
\hline \multirow{5}{*}{ Ending the project } & $S_{2} R_{4}$ & 1.14 & $S_{1} R_{19}$ & 12 & $S_{4} R_{15}$ & 7 & $S_{4} R_{15}$ & 7 \\
& $S_{2} R_{25}$ & 0.83 & $S_{2} R_{25}$ & 4 & $S_{2} R_{25}$ & 3 & $S_{2} R_{15}$ & 2 \\
& $S_{2} R_{23}$ & 0.61 & $S_{2} R_{23}$ & 2 & $S_{2} R_{23}$ & 2 & $S_{2} R_{25}$ & 1 \\
& $S_{2} R_{3}$ & 0.39 & $S_{2} R_{3}$ & 2 & $S_{2} R_{3}$ & 1 & $S_{2} R_{23}$ & 1 \\
& $S_{9} R_{24}$ & 0.29 & $S_{9} R_{24}$ & 2 & $S_{9} R_{24}$ & 1 & & \\
\hline
\end{tabular}

the static aggregation network. This, is turn, differs from the overall aggregation network risk analysis $[15,32,73]$.

Conducting a social network analysis in different project cycle stages allows the exploration of the changing rules of the stakeholder-cost risk network across the project process, revealing the deeper interactions between stakeholders and cost-based risks. This is not considered in a static aggregation network analysis. From a perspective of network development, this study identified the network as a stakeholder-cost risk network, with structural characteristics that were similar to those of the stakeholder network. Cost-related risks are attached to the risks associated with specific stakeholders and are generated and carried out by stakeholders. Therefore, the complexity of the stakeholder-cost risk network also exhibits a $U$-shaped shape with respect to horizontal development. However, precisely because the cost-related risks are linked across stakeholders, when the project develops into the construction stage, many marginal stakeholders enter the network. The cost-related risks of these marginal stakeholders do not significantly impact the full project supply chain network, making the network more sparse during the construction phase compared to the design preparation stage and at the end of the operation stage.

From a vertical point of view (i.e., network hierarchical characteristics), the most important cost risk category in the design preparation stage is excessive investment and project corruption. The key stakeholders are the owners and government departments. At the beginning of the project, the owner team must consider political and legal factors, and owners will pay a higher cost of capital for not bribing government personnel. [72] This finding is consistent with Le and Zhang et al.'s research in [74]; however, in contrast to research in China, they posited that, in the early stage of construction, land transfers, bidding, and funds management are the most significant links affected by corruption.

In studying the risk of project cost overruns, Doloi [32] noted that the important stakeholders are the government and the owners; however, that study focused on identifying the risk and did not assess the important cost-based risks. During the construction period, the owner and the contractor have the greatest impact on the risk of cost overruns of the project, and most important cost-related risks are inaccurate estimates of contractor costs, delays in contractor deadlines, and changes in material price. A stakeholder analysis found that, during the construction period, when a project enters the construction phase, the owner team will no longer participate in the cost estimation. In contrast, the contractor team will become a participant in this process [32]. This finding supports the view that effective communication among stakeholders plays an important role in accurately estimating costs [75]. Time overruns may mean additional fines for contractors and suppliers. Progress assurance plans, designed to prevent project delays among these two stakeholder groups, must be carefully designed and implemented $[45,64,66]$.

When the project enters the operation stage, the surrounding people and owners will have a greater impact. The adverse impact of construction projects on the environment and legal disputes become important cost risks. This result 


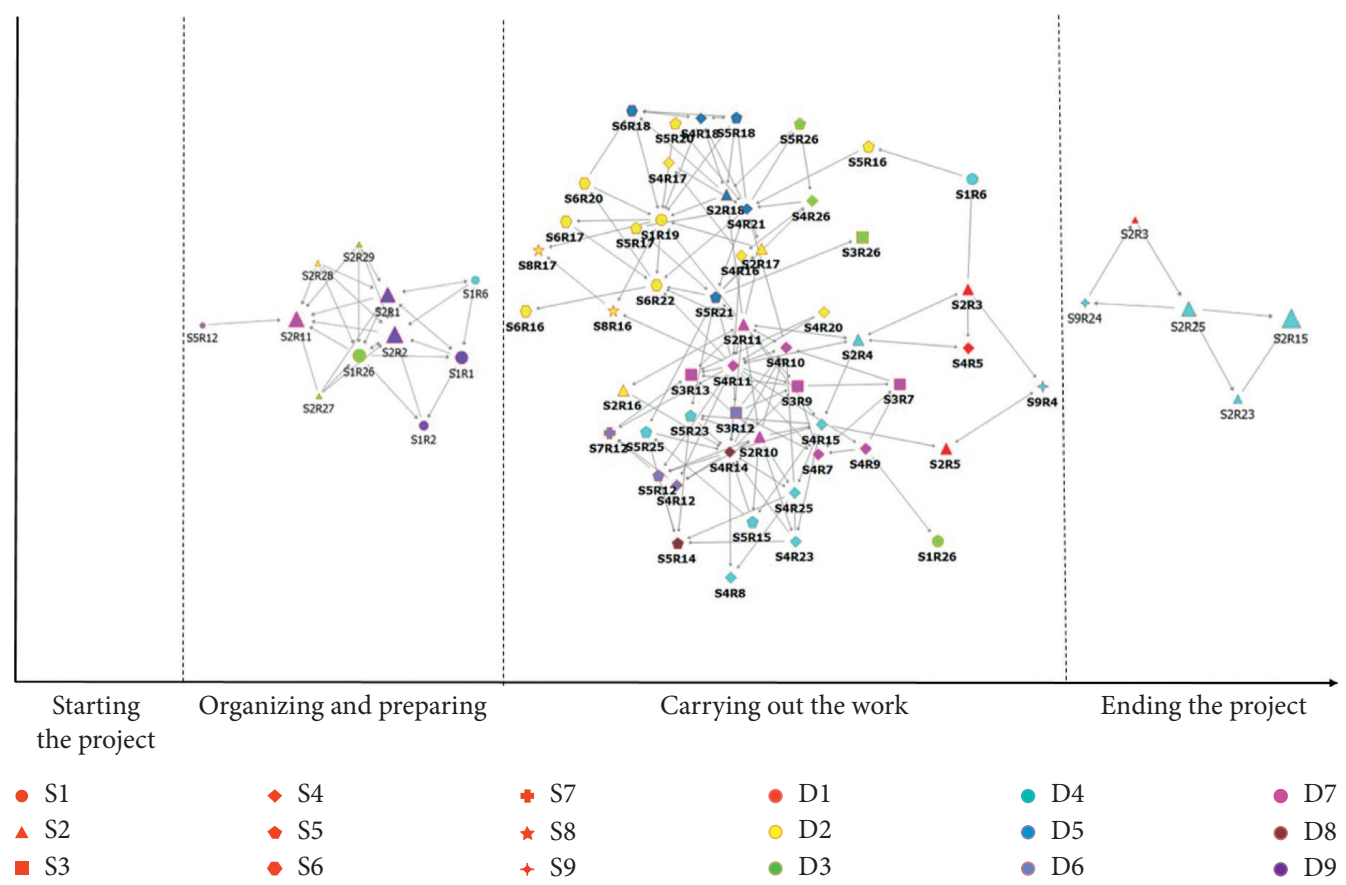

FIGURE 5: Phased cost risk network related to stakeholders.

TABLE 5: Ranking of the key risks and interactions based on centrality.

\begin{tabular}{lcccc}
\hline Project phases & Link ID & Link betweenness centrality & Index ID & Node betweenness centrality \\
\hline & $S_{2} R_{1} \longrightarrow S_{1} R_{6}$ & 8 & $S_{2} R_{1}$ & 0.1222 \\
Organizing and preparing & $S_{1} R_{26} \longrightarrow S_{1} R_{2}$ & 5.5 & $S_{1} R_{26}$ & 0.0722 \\
& $S_{2} R_{2} \longrightarrow S_{1} R_{26}$ & 4.5 & $S_{2} R_{2}$ & 0.0555 \\
& $S_{1} R_{1} \longrightarrow S_{2} R_{1}$ & 4 & $S_{1} R_{1}$ & 0.0277 \\
& $S_{1} R_{2} \longrightarrow S_{2} R_{2}$ & 4 & $S_{1} R_{29}$ & 0.0111 \\
\hline \multirow{5}{*}{ Carrying out the work } & $S_{4} R_{10} \longrightarrow S_{2} R_{11}$ & 197.7 & $S_{4} R_{10}$ & 0.1638 \\
& $S_{4} R_{10} \longrightarrow S_{4} R_{11}$ & 164.8 & $S_{5} R_{21}$ & 0.1550 \\
& $S_{4} R_{14} \longrightarrow S_{4} R_{10}$ & $S_{4} R_{21}$ & 0.1532 \\
& $S_{4} R_{16} \longrightarrow S_{4} R_{11}$ & $S_{4} R_{11}$ & 0.1254 \\
& $S_{4} R_{10} \longrightarrow S_{4} R_{21}$ & $S_{2} R_{11}$ & 0.1154 \\
\hline \multirow{5}{*}{ Ending the project } & $S_{2} R_{3} \longrightarrow S_{2} R_{25}$ & 156.2 & $S_{2} R_{25}$ & $S_{2} R_{3}$ \\
& $S_{9} R_{24} \longrightarrow S_{2} R_{3}$ & $S_{9} R_{24}$ & 0.5833 \\
& $S_{2} R_{25} \longrightarrow S_{9} R_{24}$ & 7 & & 0.2500 \\
& $S_{2} R_{23} \longrightarrow S_{2} R_{25}$ & 5 & 3 & 0.1667 \\
\hline
\end{tabular}

supports Flyvbjerg's [3] research on the cost-related risks of large-scale transport infrastructure projects. Cost and time overruns may be caused by subsequent changes in the environment; contractors and owners need to invest effort to control the situation. However, most studies, such as those by Fugar and Agyakwah-Baah [45] and Desai [44], have not fully considered these factors when ranking the relative importance of different cost risks. This previous research gap may have adversely affected the efficiency of risk management [15].

\section{Conclusion}

Based on social network theory and classical risk management methods, this study divided the project construct into four different stages and applied SNA to study the potential network of cost-related overrun risks related to stakeholders in the project construction supply chain. Through a literature analysis and interviews with key stakeholders, the costrelated risks in a project's supply chain system of the project were compiled to generate a risk list containing individual factors. A network analysis identified the key risks and interactions having a significant direct or indirect impact on other risks at different stages.

This study found that, in the predesign preparation stage of the project, the government and the owner are the most important stakeholders. During the construction phase, the most important stakeholders are the contractor and the owner. At the end of the operation phase, the surrounding population becomes more important compared to other stakeholders. For cost-related risk management, there are 
different management priorities in different stages, including owner cost estimates and government corruption in the design preparation stage, contractor cost estimates and delays in the construction stage, and the adverse impact of the project on the environment at the end of the operation phase. Managers should consider these challenges in the process of project cost management.

6.1. Theoretical Implications. From a theoretical perspective, this study contributes to the knowledge system of project cost risk management. It highlights the importance of stakeholder analysis in cost-based risk management and quantifies the relationship between risks and corresponding stakeholders by dividing the project into four different development stages. Compared with other types of risks in construction projects, cost-related risks can be significantly affected by project stakeholders and mitigated through appropriate stakeholder coordination. To rank the relative importance of cost-based risk, the whole-project aggregation network was divided into four different stages to develop a stakeholder-cost risk network. This enabled the exploration of the complex structure and interaction between risks using the SNA method and the assessment of the most important and most impactful cost-related risks in different project stages.

6.2. Practical Implications. In terms of practical impact, this study can assist practitioners across the engineering construction supply chain to manage and reduce cost-related risks. First, in the design preparation stage, the problem of government engineering corruption is extremely important. Corruption harms the government; as such, owners and contractors also need to control corruption and must work together to formulate relevant policies and mechanisms to prevent it. Reasonable reporting, oversight, and inspection mechanisms are effective methods. Owners need a sound cost assessment team and experienced project managers to make cost estimations as accurate as possible. During the construction phase, the contractor should establish an early warning mechanism for delays and an exemption memorandum to address delays caused by natural disasters such as extreme weather. To estimate contractor cost estimates, we need experienced managers and a more stable partnership with respect to prices to obtain a stable supply of elements, as well as strict contracts to avoid losses. Good environmental protection measures are essential at the end of the operation phase. Finally, to train corresponding talent, a large talent reserve can alleviate the cost-driven risks across a full project's supply chain. Supply chain stakeholders should increase their investment in education to ensure a sufficient overall talent reserve at each link of the supply chain.

6.3. Limitations and Future Work. The study used interviews and a literature review to identify key cost-related risks in engineering construction supply chains, applied a social network analysis method to rank these cost-related risks and generate important risks, and discussed the methods to avoid cost risks. Like all studies, this research had some limitations, which highlight needs for future research. First, because of the complexity and uniqueness of the project, this survey may not cover all the potential situations and cost risks in construction project supply chains. Future research could explore a wider range of cost-related risks. Second, this study used a small sample survey, which may affect the robustness of study results. A larger survey sample size should be considered in future research. Finally, the universality of the final results may be limited, because the data in this study were limited to specific regions of China. Future studies should explore whether this study's findings can be reused in other countries' environments. Despite these limitations, this work has significance and impact for both academia and practice because of its dynamic social network perspective.

\section{Data Availability}

The data used to support the findings of this study are available from the corresponding author upon request.

\section{Conflicts of Interest}

The authors declare that they have no conflicts of interest.

\section{Acknowledgments}

This study was supported by the National Natural Science Foundation of China (Project nos. 71972018, 71561009, and 71901101), the Fundamental Research Funds for the Central Universities, China (Project nos.: 2020CDJSK01TD02 and 2662018QD006), and the Fellowship of China Postdoctoral Science Foundation (Project no: 2020M671134).

\section{References}

[1] K. B. Salling and S. Leleur, "Accounting for the inaccuracies in demand forecasts and construction cost estimations in transport project evaluation," Transport Policy, vol. 38, no. 2, pp. 8-18, 2015.

[2] P. Boateng, Z. Chen, and S. O. Ogunlana, "An analytical network process model for risks prioritisation in megaprojects," International Journal of Project Management, vol. 33, no. 8, pp. 1795-1811, 2015.

[3] B. Flyvbjerg, M. S. Holm, and S. Buhl, "Underestimating costs in public works projects:error or lie?" Journal of the American Planning Association, vol. 68, no. 3, pp. 279-295, 2002.

[4] G. Wang, P. Wu, X. Wu, H. Zhang, Q. Guo, and Y. Cai, "Mapping global research on sustainability of megaproject management: a scientometric review," Journal of Cleaner Production, vol. 259, Article ID 120831, 2020.

[5] L. Lehtiranta, "Relational risk management in construction projects: modeling the complexity," Leadership and Management in Engineering, vol. 11, no. 2, pp. 141-154, 2011.

[6] H. Hwang, "Project network management: risks and contributors from the viewpoint of contractors and sub-contractors," Technological \& Economic Development of Economy, vol. 22, no. 4, pp. 631-648, 2016.

[7] L. Lehtiranta, "Risk perceptions and approaches in multiorganizations: a research review 2000-2012," International 
Journal of Project Management, vol. 32, no. 4, pp. 640-653, 2014.

[8] G. D. Wu, "Project-based supply chain cooperative incentive based on reciprocity preference," International Journal of Simulation Modelling, vol. 13, no. 1, pp. 102-115, 2013.

[9] P. Littau, N. J. Jujagiri, and G. Adlbrecht, "25 years of stakeholder theory in project management literature (1984-2009)," Project Management Journal, vol. 41, no. 4, pp. 17-29, 2010.

[10] S. Olander, "Stakeholder impact analysis in construction project management," Construction Management and Economics, vol. 25, no. 3, pp. 277-287, 2007.

[11] L. Yun, J. Wan, G. Wang, J. Bai, and B. Zhang, "Exploring the missing link between top management team characteristics and megaproject performance," Engineering, Construction and Architectural Management, vol. 27, no. 5, pp. 1039-1064, 2020.

[12] M. Shih, "The evolving law of disputed relocation: constructing inner-city renewal practices in Shanghai, 1990-2005," International Journal of Urban and Regional Research, vol. 34, no. 3, pp. 350-364, 2010.

[13] G. Wang, Q. He, B. Xia, X. Meng, and P. Wu, "Impact of institutional pressures on organizational citizenship behaviors for the environment: evidence from megaprojects," Journal of Management in Engineering, vol. 34, no. 5, pp. 1-11, 2018.

[14] K. Y. Mok, R. J. Yang, and K. Yang, "Addressing stakeholder complexity and major pitfalls in large cultural building projects," International Journal of Project Management, vol. 35, no. 3, pp. 463-478, 2017.

[15] T. Yu, G. Q. Shen, Q. Shi, Q. Lai, C. Z. Li, and K. Xu, "Managing social risks at the housing demolition stage of urban redevelopment projects: a stakeholder-oriented study using social network analysis," International Journal of Project Management, vol. 35, no. 6, pp. 925-941, 2017.

[16] G. Wu, "Knowledge collaborative incentive based on interorganizational cooperative innovation of project-based supply chain," Journal of Industrial Engineering and Management, vol. 6, no. 4, pp. 1065-1081, 2013.

[17] X. Xue, Y. Wang, Q. Shen, and X. Yu, "Coordination mechanisms for construction supply chain management in the Internet environment," International Journal of Project Management, vol. 25, no. 2, pp. 150-157, 2007.

[18] Y. Li and Y. Lu, "Social network model of complex projects organization," in Proceedings of the International Conference on Management \& Service Science, Beijing, China, September 2009.

[19] R. Freeman, Strategic Management: A Stakeholder Approach, Cambridge University Press, London, UK, 1984.

[20] G. D. Oppong, A. P. C. Chan, and A. Dansoh, "A review of stakeholder management performance attributes in construction projects," International Journal of Project Management, vol. 35, no. 6, pp. 1037-1051, 2017.

[21] S. W. N. Xia, R. Zhong, C. Wu, and X. Wang, "Assessment of stakeholder-related risks in construction projects: integrated analyses of risk attributes and stakeholder influences," Journal of Construction Engineering and Management, vol. 143, no. 8, Article ID 04017030, 2017.

[22] P. Johansson, "Implementing stakeholder management: a case study at a micro-enterprise," Measuring Business Excellence, vol. 12, no. 3, pp. 33-41, 2008.

[23] R. J. Yang and P. X. W Zhou, "Stakeholder-associated risks and their interactions in complex green building projects: a social network model," Building and Environment, vol. 73, no. 1, pp. 208-222, 2014.
[24] K. Davis, "Different stakeholder groups and their perceptions of project success," International Journal of Project Management, vol. 32, no. 2, pp. 189-201, 2014.

[25] G. Q. Yang and R. J. Shen, "Framework for stakeholder management in construction projects," Journal of Management in Engineering, vol. 31, Article ID 04014064, 2015.

[26] F. Guo, Y. Chang-Richards, S. Wilkinson, and T. C. Li, "Effects of project governance structures on the management of risks in major infrastructure projects: a comparative analysis," International Journal of Project Management, vol. 32, no. 5, pp. 815-826, 2014.

[27] R. Fulford and C. Standing, "Construction industry productivity and the potential for collaborative practice," International Journal of Project Management, vol. 32, no. 2, pp. 315-326, 2014.

[28] G.-D. Wu and D.-Z. Tang, "Inter-organizational cooperative innovation of project-based supply chains under consideration of monitoring signals," International Journal of Simulation Modelling, vol. 14, no. 3, pp. 539-550, 2015.

[29] PMI, PMI ${ }^{\circledR}$ (Project Management Institute) Project Management Body of Knowledge (PMBOK ${ }^{\circledR}$ Guide), PMI, PA, USA, 6th edition, 2017.

[30] H. S. Y. H. Kwak and D. S. Walewski, "What can we learn from the Hoover dam project that influenced modern project management?" International Journal of Project Management, vol. 32, no. 2, pp. 256-264, 2014.

[31] S. Proost, F. Dunkerley, S. Van der Loo, N. Adler, J. Bröcker, and A. Korzhenevych, "Do the selected trans european transport investments pass the cost benefit test?" Transportation, vol. 41, no. 1, pp. 107-132, 2014.

[32] H. K. Doloi, "Understanding stakeholders' perspective of cost estimation in project management," International Journal of Project Management, vol. 29, no. 5, pp. 622-636, 2011.

[33] Y. Tang, Y. Chen, Y. Hua, and Y. Fu, "Impacts of risk allocation on conflict negotiation costs in construction projects: does managerial control matter?" International Journal of Project Management, vol. 38, no. 3, pp. 188-199, 2020.

[34] D. L. A. Altshuler, "Mega-projects: the changing politics of urban public investment," International Journal of Public Sector Management, vol. 17, no. 3, 2005.

[35] S. S. Arrowsmith, "The purpose of the EU procurement directives: ends, means and the implications for national regulatory space for commercial and horizontal procurement policies," Cambridge Yearbook of European Legal Study, vol. 14, no. 47, pp. 1-47, 2011.

[36] C. Curtis and S. Sturup, "Is there a good governance model for the delivery of contemporary transport policy and practice? An examination of Melbourne and Perth," Transport Policy, vol. 19, no. 1, pp. 8-16, 2012.

[37] S. H. L. S. Shokri, C. T. Haas, and R. C. G. Haas, "Interfacemanagement process for managing risks in complex capital projects," Journal of Construction Engineering \& Management, vol. 142, no. 2, Article ID 04015069, 2016.

[38] R. J. Yang, P. X. W. Zou, and J. Wang, "Modelling stakeholder-associated risk networks in green building projects," International Journal of Project Management, vol. 34, no. 1, pp. 66-81, 2016.

[39] B. Flyvbjerg, "Survival of the unfittest: why the worst infrastructure gets built-and what we can do about it," Oxford Review of Economic Policy, vol. 25, no. 3, pp. 344-367, 2009.

[40] Q. He, X. Chen, G. Wang et al., "Managing social responsibility for sustainability in megaprojects: an innovation transitions perspective on success," Journal of Cleaner Production, vol. 241, Article ID 118395, 2019. 
[41] D. Fang, M. Li, P. S.-W. Fong, and L. Shen, "Risks in Chinese construction market-contractors' perspective," Journal of Construction Engineering and Management, vol. 130, no. 6, pp. 853-861, 2004.

[42] G. Wang, H. Zhang, B. Xia, G. Wu, and Y. Han, "Relationship between internationalization and financial performance: evidence from ENR-listed Chinese firms," Journal of Management in Engineering, vol. 36, no. 2, pp. 1-11, 2020.

[43] M. S. El-Sayegh, "Risk assessment and allocation in the UAE construction industry," International Journal of Project Management, vol. 26, no. 4, pp. 4311-4438, 2008.

[44] R. B. M. Desai, "Critical causes of delay in residential construction projects: case study of central Gujarat region of India," International Journal of Engineering Trends and Technology, vol. 4, no. 4, pp. 762-768, 2013.

[45] F. D. Fugar and A. B. Agyakwah-Baah, "Delays in building construction projects in Ghana," Australasian Journal of Construction Economics \& Building, vol. 10, no. 1, pp. 103116, 2010.

[46] F. Yang, G. Chi, G. Wang, S. Tang, Y. Li, and C. Ju, "Untangle the complex stakeholder relationships in rural settlement consolidation in China: a social network approach," Land, vol. 9 , no. 7, p. 210, 2020.

[47] J. L. Moreno, "The sociometry reader," Revue Franaise De Sociologie, vol. 2, no. 4, 1961.

[48] A. A. Darst, "Detection of timescales in evolving complex systems," Scientific Report, vol. 6, no. 1, Article ID 39713, 2016.

[49] D. Kempe, J. Kleinberg, and A. Kumar, "Connectivity and inference problems for temporal networks," Journal of Computer and System Sciences, vol. 64, no. 4, pp. 820-842, 2002.

[50] F. An, "Building a reference combinatorial model for manets," IEEE Networks, vol. 18, no. 5, pp. 24-29, 2004.

[51] L. Li and H. An, "Global energy investment structure from the energy stock market perspective based on a heterogeneous complex network model," Applied Energy, vol. 194, pp. 648$657,2016$.

[52] C. A. L. Hilber and F. Robert-Nicoud, "On the origins of land use regulations: theory and evidence from US metro areas," Journal of Urban Economics, vol. 75, pp. 29-43, 2013.

[53] D. P. B. Turner and J. Henryks, "Community gardens: sustainability, health and inclusion in the city," Local Environment, vol. 16, no. 6, pp. 489-492, 2011.

[54] R. G. Funderburg, H. Nixon, M. G. Boarnet, and G. Ferguson, "New highways and land use change: results from a quasiexperimental research design," Transportation Research Part A: Policy and Practice, vol. 44, no. 2, pp. 76-98, 2010.

[55] H. M. Alinaitwe, J. A. Mwakali, and B. Hansson, "Factors affecting the productivity of building craftsmen-studies of uganda," Journal of Civil Engineering and Management, vol. 13, no. 3, pp. 169-176, 2007.

[56] M. A. Gross, "Conflict coaching: conflict management strategies and skills for the Individual20101T.S. Jones and R. Brinkert. Conflict coaching: conflict management strategies and skills for the individual. Thousand oaks, CA: sage 2008," International Journal of Conflict Management, vol. 21, no. 3, pp. 356-360, 2010.

[57] A. H. Al-Momani, "Construction delay: a quantitative analysis," International Journal of Project Management, vol. 18, no. 1, pp. 51-59, 2000.

[58] A. Söderholm, "Project management of unexpected events," International Journal of Project Management, vol. 26, no. 1, pp. 80-86, 2008.
[59] S. Ghosh and J. Jintanapakanont, "Identifying and assessing the critical risk factors in an underground rail project in Thailand: a factor analysis approach," International Journal of Project Management, vol. 22, no. 8, pp. 633-643, 2004.

[60] C. Kaliba, M. Muya, and K. Mumba, "Cost escalation and schedule delays in road construction projects in Zambia," International Journal of Project Management, vol. 27, no. 5, pp. 522-531, 2009.

[61] T. Y. Lo, I. W. Fung, and K. C. Tung, "Construction delays in Hong Kong civil engineering projects," Journal of Construction Engineering and Management, vol. 132, no. 6, pp. 636649, 2006.

[62] F. M. Arain, S. Assaf, and L. S. Pheng, "Causes of discrepancies between design and construction," Architectural Science Review, vol. 47, no. 3, pp. 237-249, 2004.

[63] G. G. C. Brockmann, Complexity of Megaprojects, pp. 219230, CIB World Building Congress, Cape Town, South Africa, 2007.

[64] K. Nielsen and R. Randall, "Opening the black box: presenting a model for evaluating organizational-level interventions," European Journal of Work and Organizational Psychology, vol. 22, no. 5, pp. 601-617, 2013.

[65] D. Arditi, G. T. Akan, and S. Gurdamar, "Cost overruns in public projects," International Journal of Project Management, vol. 3, no. 4, pp. 218-224, 1985.

[66] J.-B. Yang and P.-R. Wei, "Causes of delay in the planning and design phases for construction projects," Journal of Architectural Engineering, vol. 16, no. 2, pp. 80-83, 2010.

[67] L. F. Alarcón, A. Rodríguez, and C. Mourgues, "Impact of machine-failure costs on equipment replacement policies: tunneling company case study," Journal of Construction Engineering and Management, vol. 138, no. 6, pp. 767-774, 2012.

[68] W. Haynes, "Transportation at the millennium: in search of a megaproject lens," Review of Policy Research, vol. 19, no. 2, pp. 62-89, 2002.

[69] G. A. Hodge, "The risky business of public-private partnerships," Australian Journal of Public Administration, vol. 63, no. 4, pp. 37-49, 2004.

[70] Y. Frimpong, J. Oluwoye, and L. Crawford, "Causes of delay and cost overruns in construction of groundwater projects in a developing countries; Ghana as a case study," International Journal of Project Management, vol. 21, no. 5, pp. 321-326, 2003.

[71] G. Cheng and C. G. Wilmot, "Louisiana highway construction cost trend after hurricanes katrina and rita," Journal of Construction Engineering and Management, vol. 135, no. 7, pp. 594-600, 2009.

[72] J. Cirilovic, N. Vajdic, and G. Mladenovic, "Developing cost estimation models for road rehabilitation and reconstruction: case study of projects in europe and central asia," Journal of Construction Engineering \& Management, vol. 140, no. 3, 2013.

[73] K. Y. Mok, G. Q. Shen, and J. Yang, "Stakeholder management studies in mega construction projects: a review and future directions," International Journal of Project Management, vol. 33, no. 2, pp. 446-457, 2015.

[74] R. S. Burt, "The network structure of social capital," Research in Organizational Behavior, vol. 22, pp. 345-423, 2000.

[75] A. Frank, "Why NASA's management doesn't believe the cost estimate," Engineering Management Journal, vol. 14, no. 1, pp. 7-12, 2002. 